\title{
Simultaneous Determination and Pharmacokinetics of Four Coumarins in Rat Plasma after Oral Administration of Traditional Chinese Medicine "YIGONG" Capsule by SPE-HPLC
}

\author{
Chao Feng, Jin-Lan Ruan* and Ya-Ling Cai \\ Hubei Key Laboratory of Natural Medicinal Chemistry and Resource Evaluation, \\ College of Pharmacy, Tongji Medical Center of Huazhong University of Science and Technology, \\ Wuhan 430030, People's Republic of China
}

\begin{abstract}
Foi desenvolvido um método simples, sensível e rápido de extração em fase sólida utilizando cromatografia liquida de alta eficiência (SPE-CLAE) para a determinação simultânea de quatro cumarinas, psoralen, isopsoralen, imperatorina e isoimperatorina, utilizando ostole como padrão interno. Utilizando este método, foi analisada a farmacocinética destas cumarinas em plasma de ratos após administração oral de uma cápsula "YIGONG" da medicina chinesa tradicional. Amostras de plasma foram pré-tratadas com extração em fase sólida utilizando cartuchos Extract-Clean ${ }^{\mathrm{TM}}$ e a separação dos extratos foi realizada com uma coluna Eurospher $\mathrm{C}_{18}$ utilizando metanol-água como fase móvel. Os limites de quantificação foram $9,7 \mathrm{ng} \mathrm{mL}^{-1}$ para psoralen, $7,1 \mathrm{ng} \mathrm{mL} \mathrm{m}^{-1}$ para isopsoralen, 6,7 $\mathrm{ng} \mathrm{mL}^{-1}$ para imperatorina e 3,0 $\mathrm{ng} \mathrm{mL}^{-1}$ para isoimperatorina. As recuperações médias das quatro cumarinas contidas no plasma de ratos foram bem acima de $80 \%$. As precisões determinadas para 6 dias estiveram sempre dentro de $10 \%$. Concluiu-se que o método estabelecido é adequado para estudos farmacocinéticos destas quatro cumarinas em plasma de ratos.
\end{abstract}

A simple, sensitive and rapid solid-phase extraction method by using high performance liquid chromatography (SPE-HPLC) was developed for simultaneous determination of four coumarins, psoralen, isopsoralen, imperatorin and isoimperatorin using osthole as internal standard. Using this method, pharmacokinetic of these coumarins in rat plasma was analyzed after oral administration of a traditional Chinese medicine "YIGONG" capsule. Plasma samples were pretreated with solidphase extraction using Extract-Clean ${ }^{\mathrm{TM}}$ cartridges, and separation of the extracts was performed on a Eurospher $\mathrm{C}_{18}$ column using methanol-water as mobile phase. The quantification limits for psoralen, isopsoralen, imperatorin and isoimperatorin in rat plasma were 9.7, 7.1, 6.7 and $3.0 \mathrm{ng} \mathrm{mL} \mathrm{m}^{-1}$, respectively. Average extract recoveries of the four coumarins from rat plasma were all over $80 \%$. Precisions determined from 6 days were all within $10 \%$. It was concluded that the established method is suitable for pharmacokinetic studies of these four coumarins in rat plasma.

Keywords: coumarins, SPE-HPLC, pharmacokinetics

\section{Introduction}

Traditional medicine has been applied in China for thousands of years through which a whole system of disease theories, diagnostic methods, treatment procedures, and drug therapies has evolved. This system is called traditional Chinese medicine (TCM). Though TCM played certain role in Chinese history and in the growth of the people, in light of modern science TCM - especially its disease theories - has been proven largely primitive, empirical, subjective, and unreliable. However, certain aspects of

*e-mail: jinlan8152@163.com
TCM should be acknowledged and recognized. Therapeutic mixtures or drug formulas are widely prescribed in TCM for treatment and prevention of diseases. These drug formulas generally consist of several ingredients, most of which are natural products such as herbal plants, animal organs or minerals. Quantities of these drug recipes are large and their effectiveness varies enormously. A large part of them has been dismissed as useless and even found to be toxic, while others have proven efficacious against certain disease conditions. Thus, tremendous efforts have so far been made to screen out those efficacious drug recipes, identify the active substances underlying their therapeutic effects, and find out the mechanism(s) of action. However, this purpose 
is not easily achieved since most formulas have multiple components, each of which in itself might also contain tens or even hundreds of chemical ingredients. This problem highlights the urgent need of sensitive, reliable and efficient methods for analysis of drug in preparations as well as in biological samples. ${ }^{1,2}$ Endeavor has been made in this paper to achieve it.

The authors have studied a TCM formula named YiGong-Ning-Xue oral solution which consists of ingredients from twelve herbal plants including Radix fructus psoraleae, Coastal glehnia root, Radix polygoni multiflori, Fructus ligustri lucidi, Fructus schisandrae, Radix rubiae, Herba leonuri, Radix glycyrrhizae etc. Yi-Gong-Ning-Xue in line with State Food and Drug Administration Standard WS-5092 (B-0092)-2002) is commercially available. The capsule form of this formula (YGC) is used in our study. YGC is held in TCM to be able to restore vital energy, nourish YIN, and promote kidney function and homeostasis. It is also often prescribed as adjunctive treatment for some gynecological illnesses like menometrorrhagia, prolonged and/or irregular menstruation. In a previous study, the authors demonstrated that coumarins such as psoralen, isopsoralen, imperatorin and isoimperatorin are a major group of ingredients of YGC. ${ }^{3}$ These coumarins have been reported to be able to inhibit platelet aggregation and proliferation of vascular smooth muscle cells. ${ }^{4}$ Some studies also claim that these coumarins benefit therapeutically in the treatment of menstrual irregularities, abdominal and menstrual cramps, vaginal discharge, menopause related disturbances. ${ }^{5}$ Several published papers have analyzed the pharmacokinetics of some active constituents from a number of herbal medicines. ${ }^{6-10}$ In this paper, the authors have developed a solid-phase extraction high performance liquid chromatography based method (SPE-HPLC) to simultaneously determine these four coumarins in rat plasma. Furthermore, the method is applied to investigate the pharmacokinetics of these coumarins in rat plasma after oral administration of YGC.

\section{Experimental}

\section{Materials}

Sample YGC was supplied by Hubei Shientang Pharmaceutical Co. Ltd. (Hubei, China). Standard substances (psoralen, isopsoralen, imperatorin, isoimperatorin, fluocinonide, bergapten and byak-angelicin) and osthole (internal standard, I.S.) were provided by National Institute for the Control of Pharmaceutical and Biological Products (Beijing, China). Male Sprague-Dawley rats were obtained from Experimental Animals Center, Tongji Medical
College, Huazhong University of Science and Technology. HPLC grade methanol and acetonitrile were purchased from Merck (Darmstadt, Germany). Other reagents were all of analytical grade. HPLC-grade water was purified by Milli-Q system (Milford, MA, USA).

\section{Chromatographic system}

Waters 2695 Alliance HPLC system series with Empower software (Waters Technologies, USA) equipped with a quaternary solvent delivery pump, an online vacuum degasser, an autosampler, a thermostated compartment and a model 2996 diode array detector, were used for chromatographic analysis. All separations were carried out on a Eurospher $\mathrm{C}_{18}$ column $(250 \mathrm{~mm} \times 4.6 \mathrm{~mm}$ i.d. with $5.0 \mu \mathrm{m}$ particle size) from Hanbang Science and Technology (Jiangsu, China). Mobile phase was methanolwater. A gradient program was applied as follows. A linear gradient of methanol-water $(53: 47, \mathrm{v} / \mathrm{v})$ was used for the first 13 min followed by holding at methanol-water $(73: 27, \mathrm{v} / \mathrm{v})$ for $17 \mathrm{~min}$. Flow-rate was $1.0 \mathrm{~mL} \mathrm{~min}^{-1}$ and column temperature was maintained at $30^{\circ} \mathrm{C}$. Effluent was monitored at $250 \mathrm{~nm}$ and injection volume was $20 \mu \mathrm{L}$. Peak identification was based on the retention time and the DAD spectrum against the standard present in the chromatogram.

Preparation of calibration standards and quality control samples

Standard stock solutions of psoralen, isopsoralen, imperatorin, isoimperatorin and osthole (I.S.) were prepared separately at concentrations of 3.100, 2.800, $0.810,0.300$ and $0.15 \mathrm{mg} \mathrm{mL}^{-1}$ in methanol and stored away from light at $4{ }^{\circ} \mathrm{C}$. Stock solutions were appropriately diluted to prepare a series of standard working solutions. Stock solution of osthole (I.S.) was also diluted in methanol to give a final concentration of $0.5 \mu \mathrm{g} \mathrm{mL} \mathrm{m}^{-1}$.

Calibraton curves were prepared by spiking $300 \mu \mathrm{L}$ drug-free control rat plasma containing $0.01 \mu \mathrm{g}$ I.S. using the standard working solutions. For each coumarin, seven calibration standards were prepared covering the following concentration range: $0.0097-3.100 \mu \mathrm{gL}^{-1}$ for psoralen, $0.0071-2.800 \mu \mathrm{g} \mathrm{mL}^{-1}$ for isopsoralen, $0.0067-0.810 \mu \mathrm{g} \mathrm{mL}^{-1}$ for imperatorin, $0.0030-0.300 \mu \mathrm{g} \mathrm{mL}^{-1}$ for isoimperatorin.

Quality control (QC) samples of each coumarin were prepared in blank plasma at high, medium and low concentration: psoralen $\left(3.100 \mu \mathrm{g} \mathrm{mL}^{-1}, 0.310 \mu \mathrm{g} \mathrm{mL}^{-1}\right.$ and $\left.0.031 \mu \mathrm{g} \mathrm{mL}^{-1}\right)$, isopsoralen $\left(2.800 \mu \mathrm{g} \mathrm{mL}^{-1}, 0.280 \mu \mathrm{g} \mathrm{mL}^{-1}\right.$ and $\left.0.028 \mu \mathrm{g} \mathrm{mL}^{-1}\right)$, imperatorin $\left(0.810 \mu \mathrm{g} \mathrm{mL}^{-1}\right.$, $0.081 \mu \mathrm{g} \mathrm{mL}^{-1}$ and $0.016 \mu \mathrm{g} \mathrm{mL}^{-1}$ ) and isoimperatorin $\left(0.300 \mu \mathrm{g} \mathrm{mL}^{-1}, 0.030 \mu \mathrm{g} \mathrm{mL}^{-1}\right.$ and $\left.0.010 \mu \mathrm{g} \mathrm{mL}^{-1}\right)$. 


\section{Extraction procedure}

Extract-Clean ${ }^{\mathrm{TM}}$ cartridges $(100 \mathrm{mg}, 1.5 \mathrm{~mL}$, Alltech Associates Inc.) were applied for pre-concentration and extraction of coumarins from rat plasma. Conditioning was first done by flushing the cartridge with methanol followed by deionized water. A mixture of $300 \mu \mathrm{L}$ plasma samples containing $0.01 \mu \mathrm{g}$ I.S. was transferred into a SPE column cartridge, the cartridge was washed with water after complete sample absorption. Then the compounds were eluted with $5 \mathrm{~mL}$ of methanol-water (53:47, v/v). The obtained eluate was evaporated dry in nitrogen at $37{ }^{\circ} \mathrm{C}$ and redissolved in $0.1 \mathrm{~mL}$ methanol. Following mixing by sonication and centrifuging at $6600 \mathrm{~g}$ for $10 \mathrm{~min}$, $20 \mu \mathrm{L}$ of the sample was injected into HPLC system for analysis.

\section{Validation of the assay}

The linearity of the prepared standards was assessed by means of linear regression analysis, using least-square regression method. The statistical significance of regression was evaluated using the ANOVA table constructed from equations shown in Table S1 (see Supplementary Information, SI) and by adjustment of the linear model (ALM), validity of the regression (VR) and efficiency of the regression (ER) tests (see Table S2, SI), according to method developed previously. ${ }^{11}$

QC samples at low, middle, and high concentrations were assayed at a two-hour interval on the same day to examine the intra-day precision and accuracy. Assays were also performed on a daily basis within the same period to determine the inter-day precision and accuracy. For sensitivity determination, a series of diluted plasma standard samples were prepared and analyzed.

The limit of quantification (LOQ) was determined as the final concentration that produced a signal-to-noise (S/N) ratio of 10 and the limit of detection (LOD) as the final concentration that produced a signal-to-noise $(\mathrm{S} / \mathrm{N})$ ratio of 3. The recoveries were determined by comparing the QC samples with drug-free plasma samples which were extracted using the same SPE procedure but spiked before nitrogen evaporation. I.S. solution was added before SPE procedure in all cases. QC samples were also checked for stability during storing and processing. ${ }^{12}$

The froze-thaw stability was examined after three freeze and thaw cycles. In each cycle the QC samples were analyzed without being frozen at first, and then stored at $-20{ }^{\circ} \mathrm{C}$ and thawed at the room temperature without any assistance. Long term stability of samples was determined after $2,5,10,15,30$ days of storage at $-20^{\circ} \mathrm{C}$. Samples for short term stability were kept at room temperature for $0-8 \mathrm{~h}$ and the assays were performed at 0, 2, 4, 6, $8 \mathrm{~h}$.

\section{Preparation of $Y G C$}

YGC $(0.5 \mathrm{~g})$ was extracted with $20.00 \mathrm{~mL}$ solvent composed of ( $80 \%$ methanol in water, $\mathrm{v} / \mathrm{v})$ for $30 \mathrm{~min}$ in an ultrasonic bath, which was repeated for three times. After cooling, the extraction was filtered, concentrated, and then dried in a rotatory evaporator under reduced pressure to yield a residue which was subsequently stored at $-20{ }^{\circ} \mathrm{C}$ before use. Coumarin contents in YGC were quantitatively determined to calculate the administered dosage of four coumarins. Extraction residue was dissolved in methanol by ultrasonication and transferred to a $10 \mathrm{~mL}$ volumetric flask. This solution was diluted to a appropriate concentration, filtered through a syringe filter $(0.45 \mu \mathrm{m})$ and then injected into the HPLC system for analysis. The contents of four coumarins (psoralen, isopsoralen, imperatorin and isoimperatorin) in the residue of YGC were 19.7, 18.5, 14.6 and $6.1 \%$, respectively, determined from peak area ratios using a linear regression equation obtained from the calibration curve.

\section{Application to pharmacokinetic studies}

Male Sprague-Dawley rats $(200 \pm 20 \mathrm{~g})$ were kept in environmental controlled breeding room for 4 days until the experiment. The rats were without feeding for $12 \mathrm{~h}$ prior to YGC content administration. YGC content was orally administered at a dose of $80 \mathrm{mg} \mathrm{kg}^{-1}$. Venous blood $(300 \mu \mathrm{L})$ was obtained from the tail vein and collected in heparin pretreated test tubes at $0.25,0.5,75,1,2,3,4,5$, $6,9,12$ and $24 \mathrm{~h}$ after YGC content administration. All blood samples were immediately centrifuged and obtained plasma was stored at $-20{ }^{\circ} \mathrm{C}$ until analysis.

HPLC analysis procedure was applied to analyze plasma concentration-time profiles of psoralen, isopsoralen, imperatorin and isoimperatorin. All data were processed by two-compartmental analysis using DAS 2.0 software package (Chinese Pharmacological Society).

\section{Results and Discussion}

\section{Method development}

Three different methods for preparation of plasma sample, i.e., protein precipitation, liquid-liquid extraction method and solid-phase extraction (SPE) were compared in a preliminary study to achieve maximum recovery and 
best resolution of each analyte. Protein precipitation by methanol, ethanol, acetonitrile or $10 \%$ trichloroacetic acid results in no chromatographic peak signal. Then several extraction solvents were tested, including ethyl ether, ethyl acetate and chloroform. It was found that liquid-liquid extraction technique resulted in a relative low recovery for four coumarins. Therefore, SPE method, using Extract-Clean ${ }^{\mathrm{TM}}$ cartridges was developed for HPLC analysis. Compared with the other extraction techniques, SPE not only yielded cleaner samples but also gave better recoveries of all four analytes.

\section{Selection of internal standard}

Osthole was selected as the I.S. because of its structural similarity to the analytes and its excellent chromatographic properties. Some other compounds such as fluocinonide, bergapten and byak-angelicin were also been tested with a mobile phase of methanol-water $(70: 30, v / v)$, acetronitrile-water (55:45, v/v), acetronitrilemethanol-water-acetic acid (20:15:65:2, v/v/v/v) at a flowrate of $1.0 \mathrm{~mL} \mathrm{~min}^{-1},{ }^{13-15}$ but without satisfactory results. Due to its better separation from the analytes, osthole was selected as the I.S. HPLC conditions were developed to give the best peak resolution of each analyte.

\section{Selectivity and chromatography}

HPLC method described, in section Chromatographic system, was selective and specific for analysis of all the four coumarins in rat plasma. Typical chromatography of blank plasma, plasma respectively spiked with psoralen $3.100 \mu \mathrm{g} \mathrm{mL}^{-1}$, isopsoralen $2.800 \mu \mathrm{g} \mathrm{mL}^{-1}$, imperatorin $0.810 \mu \mathrm{g} \mathrm{mL}^{-1}$, isoimperatorin $0.300 \mu \mathrm{g} \mathrm{mL}-1$ and I.S. $0.500 \mu \mathrm{g} \mathrm{mL}^{-1}$ and plasma obtained $1 \mathrm{~h}$ after oral administration of YGC was shown in Figure 1. The purity factor which was tested by diode array detector was larger than 990.00 (the threshold). The purity test result and the analysis of the plasma samples showed that there were no endogenous substance peaks or drug metabolite peaks interfering with analytes and I.S. in terms of retention time. The retention times were 9.6, 10.5, 22.9, 25.3, and $26.7 \mathrm{~min}$ for psoralen, isopsoralen, imperatorin, I.S. and isoimperatorin, respectively.

\section{Linearity, working range and limit of detection}

Evaluation of the assays were performed with a sevenpoint calibration curve over the concentration range described in section Preparation of calibration standards and quality control samples. Blank plasma was respectively
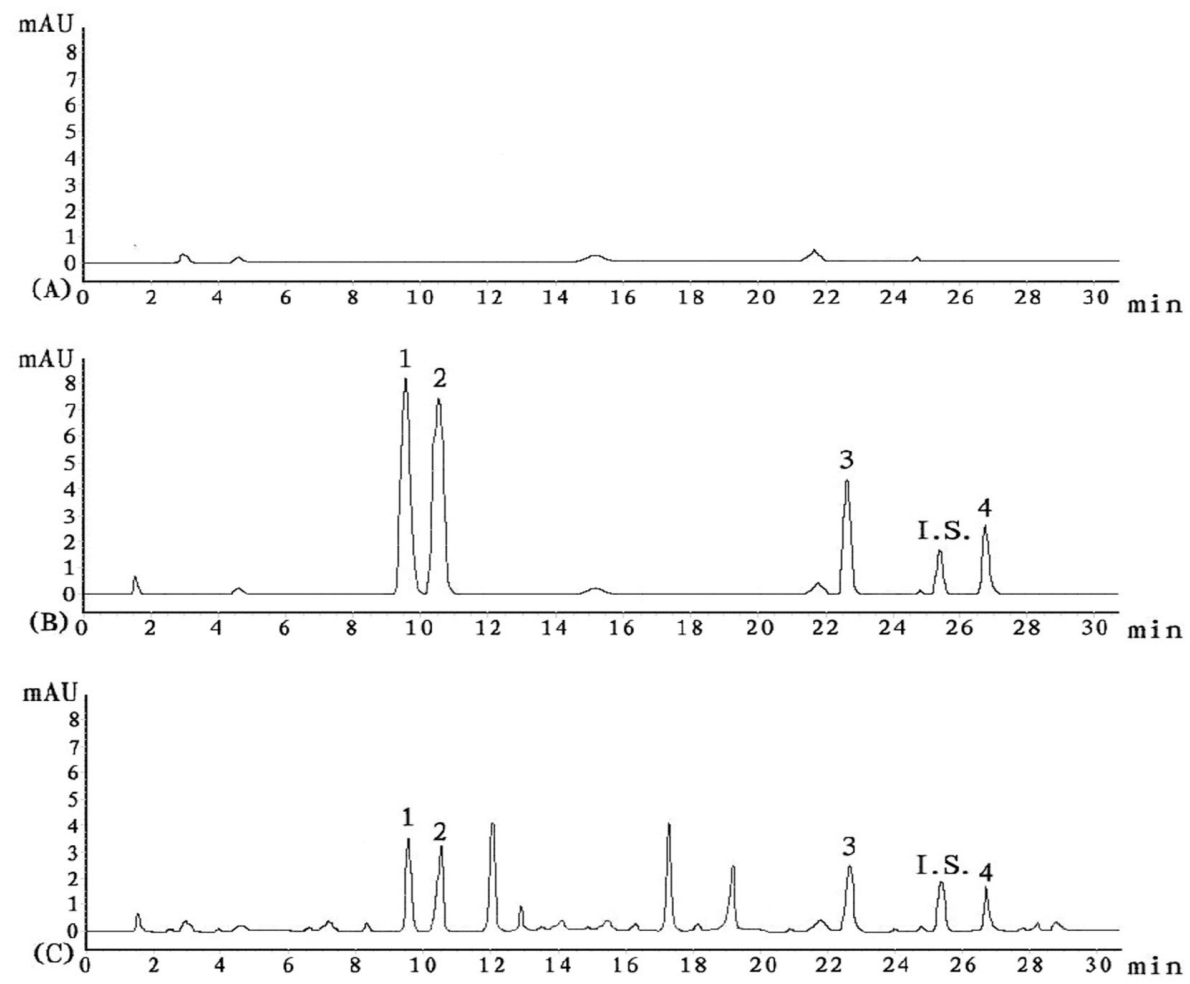

Figure 1. Chromatograms of rat plasma samples: (A) blank plasma; (B) plasma spiked with psoralen (1), isopsoralen (2), imperatorin (3), isoimperatorin (4) and osthole (I.S.); (C) plasma sample at $1 \mathrm{~h}$ after oral administration of YGC content. 
spiked with stock solutions of psoralen, isopsoralen, imperatorin, isoimperatorin to construct the calibration curve.

The standard calibration curves in the investigated range were linear, the regression data of the calibration curves, squares of correlation coefficients $\left(\mathrm{r}^{2}\right)$ and maximum squares of correlation coefficients $\left(\mathrm{r}^{2}{ }_{\text {max }}\right)$ are shown in Table S3 (SI). Table S2 (SI) summarizes the results of linearity tests for a statistical significance of $95 \%$. The adjustment of the model is considered satisfactory if $\mathrm{F}_{\text {obtained }}<\mathrm{F}_{\text {critical }}$ in the adjustment of the linear model (ALM) test. The validity of the regression (VR) test justifies that the slope of the linear regression equation is different than zero. It's indication that the $\mathrm{m}$ value is not null if $\mathrm{F}_{\text {obtained }}>>\mathrm{F}_{\text {critical }}$. The results showed that the squares of the linear correlation coefficients were above 0.99 (Table S3), evidencing the linearity occurrence. ${ }^{11}$ The regression of standard curves were statistically significant since the statistical test did not exceed the critical value. The values of $\mathrm{r}^{2}$ and $\mathrm{r}_{\text {max }}^{2}$ were similar. This indicates that the error due to regression is close to the pure error that must be due to the analytical procedure, validating the use of the linear model.

LOD of the analytes were in the range of 1.30-4.86 $\mathrm{ng} \mathrm{mL}^{-1}$, while LOQ were from 3.0-9.7 $\mathrm{ng} \mathrm{mL}^{-1}$. Detailed descriptions of the calibration curves and linear ranges, together with the values of LOD and LOQ (all were listed in Table S3, SI).

\section{Precision and accuracy}

The precision and accuracy of the assays were evaluated using quality control (QC) samples at three concentration levels described in section Validation of the assay. The precision is presented as percentage of R.S.D. and accuracy is presented as percentage of the relative error (RE) against the nominal concentration. The intra-day and inter-day precision calculated as the relative standard deviation (R.S.D.) were smaller than $10 \%$, and the corresponding RE values ranged from -14.3 to $9.7 \%$ (see in Table S4, SI). The results showed that the established method has satisfactory precision and accuracy.

\section{Absolute recovery and repeatability of extraction procedure}

To examine the absolute recovery of the SPE procedure, six replicates of QC samples at three concentration levels were used. The absolute recovery was within the range of 80.0-95.5\% (shown in Table S5, SI). Repeatability of the extraction procedure was also determined by using six replicates of the QC samples. The R.S.D. values of the extraction repeatability were all below $6.1 \%$.

\section{Stability}

Stability of psoralen, isopsoralen, imperatorin and isoimperatorin in rat plasma during sample storage and processing procedures was also evaluated. The results of the stability tests shown in Table S6 (see SI) well met the criterion for stability measurements.

\section{Application to pharmacokinetic study}

The concentrations of four coumarins in rat plasma were simultaneously determined by the described HPLC method after oral administration of YGC $\left(80 \mathrm{mg} \mathrm{kg}^{-1}\right)$ to rats. Pharmacokinetics was analyzed by using the twocompartmental method. The mean plasma concentrationtime profiles of psoralen, isopsoralen, imperatorin and isoimperatorin are shown in Figure 2. The pharmacokinetic parameters are shown in Table S7 (see SI). Plasma concentrations of psoralen, isopsoralen, imperatorin and isoimperatorin peaked at $0.75 \pm 0.21,1.00 \pm 0.32,2.00 \pm$ 0.27 and $1.00 \pm 0.36 \mathrm{~h}$, respectively after oral administration of YGC. The mean maximum concentrations $\left(C_{\max }\right)$ of psoralen, isopsoralen, imperatorin and isoimperatorin in rat plasma were $2.452 \pm 0.322,2.221 \pm 0.242,0.684 \pm$ 0.103 and $0.285 \pm 0.035 \mu \mathrm{g} \mathrm{mL}{ }^{-1}$, respectively. Elimination terminal half life $\left(\mathrm{t}_{1 / 2}\right)$ for psoralen, isopsoralen, imperatorin and isoimperatorin were $8.292 \pm 0.211,3.831 \pm 0.026$, $7.365 \pm 0.254$ and $4.841 \pm 0.105 \mathrm{~h}$, respectively. It was demonstrated that this simple and rapid method was sufficiently sensitive to follow plasma levels of psoralen, isopsoralen, imperatorin and isoimperatorin after oral administration YGC content to rats.

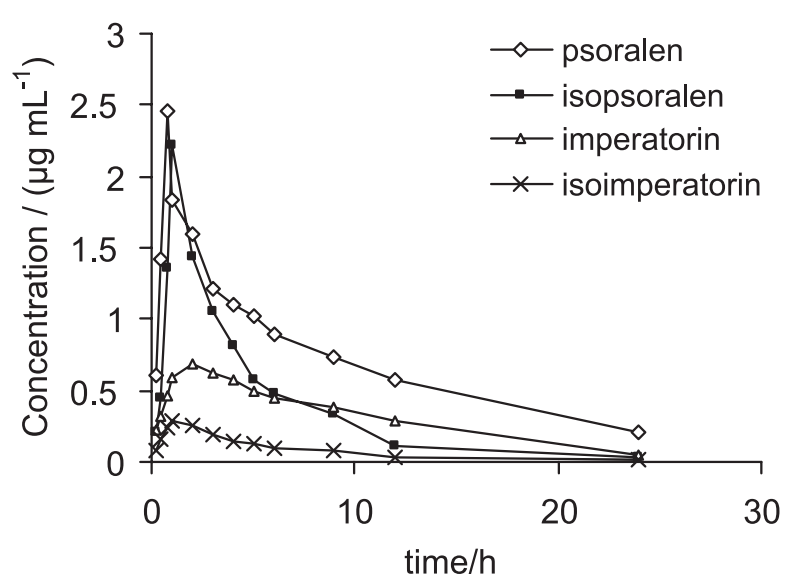

Figure 2. Mean plasma concentration-time plots of psoralen, isopsoralen, imperatorin, isoimperatorin of rats after oral administration of YGC content. 


\section{Conclusions}

A simple, sensitive and rapid SPE-HPLC method has been developed for simultaneous determination of psoralen, isopsoralen, imperatorin and isoimperatorin in rat plasma after oral administration YGC, an effectual TCM compound preparation. SPE was employed for extraction of these components from the plasma samples. The developed method provided a simple sample preparation and a stable analytical result for the determination of these coumarins in the plasma samples. A pharmacokinetic study of the main active constituents in YGC will play an important role in studying the drug interaction in vivo for investigating their synergetic effects, identifying their mechanisms of action for obtaining a more effectual and safe remedy for clinical practice.

\section{Supplementary Information}

Supplementary data is available free of charge at http://jbcs.sbq.org.br, as PDF file.

\section{References}

1. Wu, Y. J.; Chen, J. J.; Cheng, Y. Y.; Anal. Bioanal. Chem. 2005, $382,1595$.

2. Li, J.; Wang, G. J.; Li, P.; Hao, H. P.; J. Chromatogr., B 2005 , $826,26$.
3. Feng, C.; Cai, Y. L.; Ruan, J. L.; J. Pharm. Biomed. Anal. 2008, 47, 442 .

4. Chen, I. S.; Chang, C. T.; Sheen, W. S.; Teng, C. M.; Tsai, I. L.; Duh, C. Y.; Ko, F. N.; Phytochemistry 1996, 41, 525.

5. Pires, A. E.; Honda, N. K.; Cardoso, C. A. L.; J. Pharm. Biomed. Anal. 2004, 36, 415.

6. Tegeder, I.; Schmidtko, A.; Brautigam, L.; Kirschbaum, A.; Geisslinger, G.; Lotsch, J.; Clin. Pharmacol. Ther. 2002, 71, 153.

7. Zhang, J. L.; Yu, H. L.; Sheng, Y. X.; Li, L.; Ye, M.; Guo, D. A.; Biomed. Chromatogr. 2005, 19, 15.

8. Mei, Y. H.; Xu, J.; Zhao, J. H.; Feng, N. P.; Liu, Y.; Wei, L.; J. Chromatogr., B 2008, 869, 138.

9. Xia, Y. F.; Dai, Y.; Wang, Q.; Liang, H. Z.; J. Chromatogr., B 2007, 857, 332.

10. Li, X. L.; Li, X. R.; Wang, L. J.; Li, Y. H.; Xu, Y. X.; Xue, M.; J. Pharm. Biomed. Anal. 2007, 44, 1106.

11. Damasceno, L. H. S.; Adorno, M. A. T.; Hirasawa, J. S.; Varesche, M. B. A.; Zaiat, M.; J. Braz. Chem. Soc. 2008, 19, 1158.

12. Yu, k.; Ma, Y. H.; Shao, Q.; Qu, H. B.; Cheng, Y. Y.; J. Pharm. Biomed. Anal. 2007, 44, 532.

13. Li, Y. B.; J. Pharm. Biomed. Anal. 2006, 40, 1253.

14. Cardoso, C. A. L.; Pires, A. E.; Honda, N. K.; Chem. Pharm. Bull. 2006, 54, 442.

15. Xie, Y.; Chen, Y.; Lin, M.; Wen, J.; Fan, G. R.; Wu, Y. T.; J. Pharm. Biomed. Anal. 2007, 44, 166.

Submitted: February 2, 2010 Published online: September 21, 2010 


\title{
Simultaneous Determination and Pharmacokinetics of Four Coumarins in Rat Plasma after Oral Administration of Traditional Chinese Medicine "YIGONG" Capsule by SPE-HPLC
}

\author{
Chao Feng, Jin-Lan Ruan* and Ya-Ling Cai \\ Hubei Key Laboratory of Natural Medicinal Chemistry and Resource Evaluation, College of \\ Pharmacy, Tongji Medical Center of Huazhong University of Science and Technology, Wuhan \\ 430030, People's Republic of China
}

Table S1. Mean sum of squares and degrees of freedom used in F-test (ANOVA)

\begin{tabular}{|c|c|c|c|}
\hline Source of variability & Sum of squares & Degrees of Freedom & Mean Sum of Squares \\
\hline Total & $\mathrm{SQT}=\Sigma \Sigma \mathrm{y}_{i j}^{2}$ & $\mathrm{n}$ & $\mathrm{MQT}=\mathrm{SQT} / \mathrm{n}$ \\
\hline Correction ("b") & $\mathrm{FC}=\mathrm{n} \mathrm{y}_{\mathrm{on}}$ & 1 & FC \\
\hline Total correction & $\mathrm{SQC}=\Sigma \Sigma\left(\mathrm{y}_{\mathrm{i}}-\mathrm{y}_{\infty}\right)^{2}$ & $\mathrm{n}-1$ & $\mathrm{MQC}=\mathrm{SQC} /(\mathrm{n}-1)$ \\
\hline Due to regression (“a”) & $\mathrm{SQR}=\Sigma\left(\mathrm{y}_{\mathrm{i}}-\mathrm{y}_{\mathrm{\omega}}\right)^{2}$ & 1 & $\mathrm{MQR}=\mathrm{SQR}$ \\
\hline Residual & $\mathrm{SQE}=\Sigma \Sigma\left(\mathrm{y}_{i j}-\mathrm{y}_{i}\right)^{2}$ & $\mathrm{n}-2$ & $\mathrm{MQE}=\mathrm{SQE} /(\mathrm{n}-2)$ \\
\hline Pure Error & $\mathrm{SQEP}=\Sigma \Sigma\left(\mathrm{y}_{\mathrm{ij}}-\mathrm{y}_{\mathrm{i} 0}\right)^{2}$ & $n-m_{i}$ & $\mathrm{MQEP}=\mathrm{SQEP} /\left(\mathrm{n}-\mathrm{m}_{\mathrm{i}}\right)$ \\
\hline Lack-of-fit & $\mathrm{SQL}=\Sigma\left(\mathrm{y}_{\mathrm{i}}-\mathrm{y}_{\mathrm{i}}\right)^{2}$ & $m_{i}-2$ & $\mathrm{MQL}=\mathrm{SQL} /\left(\mathrm{m}_{i}-2\right)$ \\
\hline
\end{tabular}

$\mathrm{n}=$ total number of measurements; $\mathrm{m}_{\mathrm{i}}=\mathrm{i}$-concentration levels $(7) ; \mathrm{y}_{\mathrm{i}}=$ observed signal; $\mathrm{y}_{\infty \mathrm{o}}=$ mean of measured signals; $\mathrm{y}_{\mathrm{i}}=$ predicted dependent variable; $\mathrm{y}_{\mathrm{in}}=$ mean of replicates of i-concentration level; "i”" index refers to $\mathrm{x}$-independent variable; " $\mathrm{j}$ " index refers to replicates in $\mathrm{x}$-levels. First summation $\Sigma$ ranges from $i=1$ to $i=m_{i}$. Second summation $\Sigma \Sigma$ in $S Q C, S Q E$ and $S Q E P$ ranges from $i=1$ to $j=n_{\text {. }}$

Table S2. Linearity and regression efficiency tests

\begin{tabular}{|c|c|c|c|}
\hline Test & $\mathrm{F}_{\text {critical }}$ & $\mathrm{F}_{\text {obtained }}$ & Condition \\
\hline $\begin{array}{l}\text { Adjustment of the linear model } \\
\text { (ALM) }\end{array}$ & $\mathrm{F}_{\mathrm{mi}-2 ; \mathrm{n}-\mathrm{mi} ; \alpha / 2}$ & MQL/MQEP & $\mathrm{F}_{\text {obtained }}<\mathrm{F}_{\text {critical }}$ \\
\hline Validity of the regression (VR) & $\mathrm{F}_{1 ; \alpha-2 ; \alpha / 2}$ & MQR/MQE & $\mathrm{F}_{\text {obtained }}>\mathrm{F}_{\text {critical }}$ \\
\hline \multicolumn{4}{|c|}{ Efficiency of the regression (ER) } \\
\hline Efficiency $\left(r^{2}\right)$ & & SQR/SQC & \\
\hline Maximum efficiency $\left(\mathrm{r}^{2}{ }_{\max }\right)$ & & SQC/SQEP & \\
\hline
\end{tabular}

Table S3. Calibration curves for four coumarins of YGC content in rat plasma

\begin{tabular}{|c|c|c|c|c|c|c|c|c|c|c|}
\hline \multirow{2}{*}{ Components } & \multirow{2}{*}{ Calibration $(y=a x+b)$} & \multirow{2}{*}{$\begin{array}{l}\text { Linear range/ } \\
\left(\mu \mathrm{g} \mathrm{mL} L^{-1}\right)\end{array}$} & \multirow{2}{*}{$r^{2}$} & \multirow{2}{*}{$\mathrm{r}_{\max }^{2}$} & \multicolumn{2}{|c|}{ ALM } & \multicolumn{2}{|c|}{ VR } & \multirow{2}{*}{$\begin{array}{c}\text { LOD/ } \\
\left(\mathrm{ng} \mathrm{mL}^{-1}\right)\end{array}$} & \multirow{2}{*}{$\begin{array}{c}\mathrm{LOQ} / \\
\left(\mathrm{ng} \mathrm{mL}^{-1}\right)\end{array}$} \\
\hline & & & & & $\mathrm{F}_{5,14,0.025}$ & $\mathrm{~F}_{\text {obtained }}$ & $\mathrm{F}_{1,19,0.025}$ & $\mathrm{~F}_{\text {obtained }}$ & & \\
\hline psoralen & $\mathrm{y}=(112159 \pm 1265) x+(-84598 \pm 124)$ & $0.0097-3.10$ & 0.9992 & 0.9999 & \multirow{4}{*}{3.66} & 2.77 & \multirow{4}{*}{5.92} & 23731 & 4.86 & 9.7 \\
\hline isopsoralen & $y=(93295 \pm 188) x+(-81817 \pm 235)$ & $0.0071-2.80$ & 0.9941 & 0.9998 & & 2.73 & & 3201 & 3.46 & 7.1 \\
\hline imperatorin & $\mathrm{y}=(79337 \pm 179) x+(-106203 \pm 1134)$ & $0.0067-0.81$ & 0.9965 & 0.9998 & & 2.68 & & 5410 & 3.24 & 6.7 \\
\hline isoimperatorin & $y=(68869 \pm 192) x+(-51119 \pm 213)$ & $0.0030-0.30$ & 0.9987 & 0.9999 & & 2.62 & & 14596 & 1.30 & 3.0 \\
\hline
\end{tabular}

LOD is defined as the concentration where the signal-to-noise ratio is 3 , and LOQ is defined as the concentration where the signal-to-noise ratio is 10 . The slope and intercept were given as the form of mean \pm S.D.

*e-mail: jinlan8152@163.com 
Table S4. Intra-day and inter-day precision for the assay of four coumarins in rats plasma $(n=6)$

\begin{tabular}{|c|c|c|c|c|c|c|}
\hline \multirow{2}{*}{$\begin{array}{l}\text { Nominal } \\
\text { concentration / } \\
\left(\mu \mathrm{g} \mathrm{mL} L^{-1}\right)\end{array}$} & \multicolumn{3}{|c|}{ Intra-day precision } & \multicolumn{3}{|c|}{ Inter-day precision } \\
\hline & $\begin{array}{l}\text { Measured concentration } \\
\text { Mean } \pm \mathrm{SD} /\left(\mu \mathrm{g} \mathrm{mL}^{-1}\right)\end{array}$ & R.S.D / (\%) & $\mathrm{RE} /(\%)$ & $\begin{array}{l}\text { Measured concentration } \\
\text { Mean } \pm \mathrm{SD} /\left(\mu \mathrm{g} \mathrm{mL}^{-1}\right)\end{array}$ & R.S.D / (\%) & $\mathrm{RE} /(\%)$ \\
\hline \multicolumn{7}{|l|}{ psoralen } \\
\hline 3.100 & $3.140 \pm 0.010$ & 3.2 & 1.3 & $3.261 \pm 0.143$ & 4.4 & 5.2 \\
\hline 0.310 & $0.337 \pm 0.013$ & 3.9 & 8.7 & $0.340 \pm 0.028$ & 8.2 & 9.7 \\
\hline 0.031 & $0.032 \pm 0.002$ & 6.3 & 3.5 & $0.028 \pm 0.002$ & 7.1 & -9.7 \\
\hline \multicolumn{7}{|l|}{ isopsoralen } \\
\hline 2.800 & $2.696 \pm 0.075$ & 2.8 & -3.7 & $2.915 \pm 0.134$ & 4.6 & 4.1 \\
\hline 0.280 & $0.278 \pm 0.007$ & 2.5 & -0.7 & $0.296 \pm 0.014$ & 4.7 & 5.7 \\
\hline 0.028 & $0.025 \pm 0.001$ & 4.0 & -10.7 & $0.024 \pm 0.001$ & 4.2 & -14.3 \\
\hline \multicolumn{7}{|l|}{ imperatorin } \\
\hline 0.810 & $0.798 \pm 0.045$ & 5.6 & -1.5 & $0.755 \pm 0.029$ & 3.8 & -6.8 \\
\hline 0.081 & $0.079 \pm 0.002$ & 2.5 & -2.5 & $0.075 \pm 0.002$ & 2.7 & -7.4 \\
\hline 0.016 & $0.015 \pm 0.001$ & 6.7 & -6.3 & $0.014 \pm 0.001$ & 7.1 & -12.5 \\
\hline \multicolumn{7}{|l|}{ isoimperatorin } \\
\hline 0.300 & $0.283 \pm 0.016$ & 5.7 & -5.7 & $0.279 \pm 0.018$ & 6.5 & -7.0 \\
\hline 0.030 & $0.028 \pm 0.001$ & 3.6 & -6.7 & $0.031 \pm 0.002$ & 6.5 & 3.3 \\
\hline 0.010 & $0.009 \pm 0.0007$ & 7.8 & -10.0 & $0.0087 \pm 0.0007$ & 8.0 & -13.0 \\
\hline
\end{tabular}

Table S5. Absolute recovery of the developed method and repeatability of the extraction procedure $(n=6)$

\begin{tabular}{|c|c|c|c|c|}
\hline Components & $\begin{array}{c}\text { Nominal } \\
\text { concentration } /\left(\mu \mathrm{g} \mathrm{mL}{ }^{-1}\right)\end{array}$ & $\begin{array}{l}\text { Measured concentation } \\
\left.\text { Mean } \pm \mathrm{SD} /(\mu \mathrm{g} \mathrm{mL})^{-1}\right)\end{array}$ & $\begin{array}{c}\text { Recovery / } \\
(\%)\end{array}$ & $\begin{array}{l}\text { R.S.D / } \\
(\%)\end{array}$ \\
\hline \multirow[t]{3}{*}{ psoralen } & 3.100 & $2.855 \pm 0.097$ & 92.1 & 3.4 \\
\hline & 0.310 & $0.296 \pm 0.003$ & 95.5 & 1.0 \\
\hline & 0.031 & $0.027 \pm 0.0016$ & 87.1 & 6.0 \\
\hline \multirow[t]{3}{*}{ isopsoralen } & 2.800 & $2.526 \pm 0.078$ & 90.2 & 3.1 \\
\hline & 0.280 & $0.267 \pm 0.005$ & 95.4 & 1.9 \\
\hline & 0.028 & $0.024 \pm 0.0006$ & 85.7 & 2.5 \\
\hline \multirow[t]{3}{*}{ imperatorin } & 0.810 & $0.727 \pm 0.0116$ & 89.8 & 1.6 \\
\hline & 0.081 & $0.069 \pm 0.0009$ & 85.2 & 1.3 \\
\hline & 0.016 & $0.014 \pm 0.0006$ & 87.5 & 4.3 \\
\hline \multirow[t]{3}{*}{ isoimperatorin } & 0.300 & $0.254 \pm 0.012$ & 84.7 & 4.7 \\
\hline & 0.030 & $0.028 \pm 0.001$ & 93.3 & 3.6 \\
\hline & 0.010 & $0.008 \pm 0.0002$ & 80.0 & 2.5 \\
\hline
\end{tabular}


Table S6. Stability of four coumarins in rats plasma $(n=6)$

\begin{tabular}{|c|c|c|c|c|c|c|c|}
\hline \multirow{2}{*}{ Components } & \multirow{2}{*}{$\begin{array}{l}\text { Nominal concentration / } \\
\qquad\left(\mu \mathrm{g} \mathrm{mL}^{-1}\right)\end{array}$} & \multicolumn{2}{|c|}{ Three freeze-thaw stability } & \multicolumn{2}{|c|}{ Stored at $-20^{\circ} \mathrm{C}$} & \multicolumn{2}{|c|}{ Stored at ambient temperature } \\
\hline & & R.S.D / (\%) & R.E. / (\%) & R.S.D / (\%) & R.E. / (\%) & R.S.D / (\%) & R.E. / (\%) \\
\hline \multirow[t]{3}{*}{ psoralen } & 3.100 & 2.6 & -0.013 & 1.2 & -0.029 & 1.4 & -0.030 \\
\hline & 0.310 & 1.9 & 0.113 & 4.8 & 0.018 & 2.7 & 0.103 \\
\hline & 0.031 & 5.5 & -0.025 & 1.1 & -0.019 & 2.6 & -0.010 \\
\hline \multirow[t]{3}{*}{ isopsoralen } & 2.800 & 2.7 & -0.014 & 3.1 & -0.009 & 4.8 & -0.007 \\
\hline & 0.280 & 4.4 & -0.138 & 2.2 & -0.164 & 5.8 & -0.163 \\
\hline & 0.028 & 11.4 & 0.044 & 1.1 & 0.044 & 6.7 & 0.007 \\
\hline \multirow[t]{3}{*}{ imperatorin } & 0.810 & 6.2 & 0.057 & 1.4 & 0.004 & 1.9 & 0.008 \\
\hline & 0.081 & 3.7 & 0.017 & 4.6 & -0.028 & 2.6 & -0.033 \\
\hline & 0.016 & 10.6 & -0.006 & 12.8 & -0.021 & 2.2 & 0.037 \\
\hline \multirow[t]{3}{*}{ isoimperatorin } & 0.300 & 8.5 & -0.050 & 4.6 & -0.030 & 2.7 & -0.040 \\
\hline & 0.030 & 4.6 & -0.267 & 5.1 & -0.274 & 8.8 & -0.289 \\
\hline & 0.010 & 8.7 & -0.157 & 8.6 & -0.157 & 7.2 & -0.175 \\
\hline
\end{tabular}

Relative standard deviation (R.S.D) is expressed as: (standard deviation between observed concentrations/mean observed concentration) $\times 100$; Relative error (R.E.) is expressed as: (mean observed concentration/nominal concentration) $\times 100$.

Table S7. Pharmacokinetic parameters of four coumarins after oral administration of YGC content in rat, each value represents the mean \pm SD $(n=6)$

\begin{tabular}{|c|c|c|c|c|}
\hline Pharmacokinetic & psoralen & isopsoralen & imperatorin & isoimperatorin \\
\hline$K_{10} /\left(\mathrm{h}^{-1}\right)$ & $0.230 \pm 0.021$ & $0.677 \pm 0.086$ & $0.249 \pm 0.019$ & $0.347 \pm 0.046$ \\
\hline$K_{12} /\left(\mathrm{h}^{-1}\right)$ & $0.866 \pm 0.422$ & $0.437 \pm 0.023$ & $1.536 \pm 0.012$ & $0.372 \pm 0.034$ \\
\hline$K_{21} /\left(\mathrm{h}^{-1}\right)$ & $0.584 \pm 0.081$ & $0.44 \pm 0.053$ & $1.179 \pm 0.101$ & $0.408 \pm 0.097$ \\
\hline$t_{1 / 2} /(\mathrm{h})$ & $8.292 \pm 0.211$ & $3.831 \pm 0.026$ & $7.365 \pm 0.254$ & $4.841 \pm 0.105$ \\
\hline$C_{\max } /\left(\mu g \mathrm{~mL}^{-1}\right)$ & $2.452 \pm 0.332$ & $2.221 \pm 0.242$ & $0.684 \pm 0.103$ & $0.285 \pm 0.035$ \\
\hline$T_{\max } /(\mathrm{h})$ & $0.75 \pm 0.21$ & $1.00 \pm 0.32$ & $2.00 \pm 0.27$ & $1.00 \pm 0.36$ \\
\hline $\mathrm{AUC}_{0 \rightarrow \mathrm{t}} /\left(\mu \mathrm{g} \mathrm{mL} L^{-1} \mathrm{~h}^{-1}\right)$ & $16.663 \pm 2.675$ & $8.885 \pm 1.821$ & $7.564 \pm 1.324$ & $1.743 \pm 0.654$ \\
\hline $\mathrm{AUC}_{0 \rightarrow \infty} /\left(\mu \mathrm{g} \mathrm{mL}^{-1} \mathrm{~h}^{-1}\right)$ & $19.127 \pm 2.856$ & $9.036 \pm 1.956$ & $8.322 \pm 1.776$ & $1.809 \pm 0.994$ \\
\hline
\end{tabular}

$K_{10}$ : central compartment elimination rate contrant; $K_{12}$ : central to peripheral compartment rate contrant; $K_{21}$ : peripheral to central compartment rate contrant; $t_{1 / 2}$ : elimination terminal half life; $C_{\max }$ : maximum plasma concentration; $T_{\max }$ : time to reach the maximum plasma concentration; AUC ${ }_{0 \rightarrow 1}$ : area under the plasma concentration-time curve from zero to the time of the final measurable sample; $\mathrm{AUC}_{0 \rightarrow \infty}$ : area under the plasma concentration-time curve from zero to infinity. 